\title{
OREM'in Öz Bakım Eksikliği Kuramına Göre Tip I Diyabeti Olan Adölesanın Hemşirelik Bakımı
}

\author{
Öğr. Gör. Dr. Sultan Esra SAYAR \\ Atatürk Üniversitesi Sağlık Bilimler Fakültesi Ebelik Bölümü, ERZURUM
}

DOI: http://dx.doi.org/10.29228/tjdn.52305

\section{Olgu Sunumu}

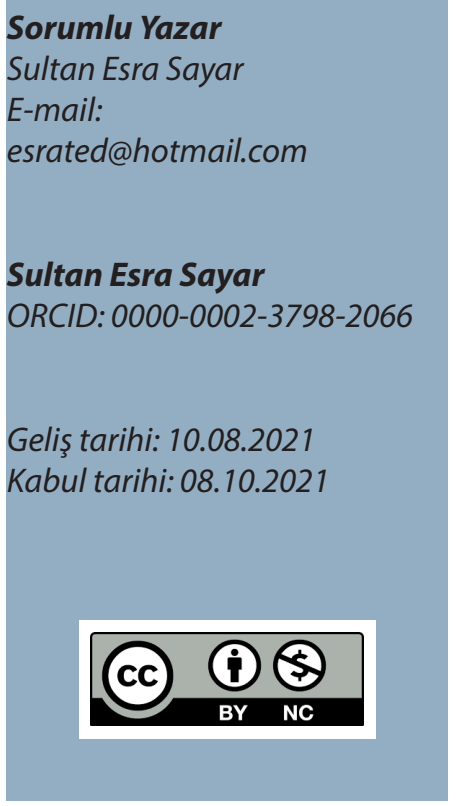

Özet

Adölesanlarda kronik hastalıkların seyri; adölesana, aileye, hastalığa, sosyal çevreye ve aldığı tıbbi bakıma göre değişmekte ve adölesanın hastalığa uyumunu kolaylaştırmakta ya da zorlaştırmaktadır. Hemşirelik kuram ve modellerinin hemşireliğin uygulama alanlarında kullanılması, bu alanlara kavramsal bir çerçeve sunarak temel olușturmaktadır. Kuram ve modeller, hemşirelik mesleğinin gelişim ve profesyonelleşmesine katkıda bulunur. Orem'in Öz Bakım Eksikliği Hemşirelik Kuramı hemşirelik uygulamalarında en sık kullanılan kuramlardan biridir. Orem'e göre hemşireler, öz bakım eksikliği durumunda bireyin gereksinimlerini karşılayabileceği düzeye getirmeli, bireyin öz bakım yeteneklerini artırmalı ya da öz bakım yetersizliğini gideremediği durumlarda da bakım gereksinimlerini kendisi üstlenmelidir. Yeni tanı almış olan ve bu duruma uyum sağlamak zorunda olan tip 1 diyabetli adölesanlar Orem'in Öz Bakım Eksikliği Hemşirelik Kuramına göre eğitsel hemşirelik yaklaşımlarına gereksinim duymaktadırlar. Bu vakada tip1 diyabet tanısı olan bir adölesanın Öz Bakım Eksikliği Hemşirelik Kuramına göre hemşirelik bakımı incelenmiştir.

Anahtar Sözcükler: Hemşirelik; Öz bakım; Hemşirelik süreci; Tip1 Diyabet

\section{Abstract}

The course of chronic diseases in adolescents; It varies according to the adolescent, family, illness, social environment and medical care, and makes it easier or difficult for the adolescent to adapt to the disease. The usage of the nursing theory and models in nursing care process offers a conceptual framework to this area forming a basis and guiding. The theory and the models contribute to the development and professionalization of the profession of nursing. Orem's Sel$f$-Care Deficit Nursing Theory is one of the most frequently used theory in the practice of nursing. According to Orem, nurses should bring the individual to a level where they can meet their needs in case of lack of self-care. The adolescent with a type 1 diabetes are in need of supportive and educational nursing approaches and guidance according to Orem's Self-Care Deficit Nursing Theory. In this review, the nursing care of a patient with type 1 diabetes is studied according to Orem's Self-Care Deficit Nursing Theory.

Keywords: Nursing; Self-care; Nursing process; Type I Diabetes

\section{Giriş}

Tip 1 diabetes mellitus (DM) çocukluk çağında en sık görülen kronik hastalıklardan biridir (Craig ve ark., 2014; Kalyva, Malakonaki, ve Mamoulakis, 2011). Son yıllarda Tip 1 DM tanısı alan çocuk ve adölesanların sayısı giderek artış eğilimi göstermektedir. Uluslararası Diyabet Federasyonu'nun (2019) verilerine göre Tip 1 diyabetli çocuk ve ergen sayısının 1,1 milyona ulaştığı belirtilmektedir. Adölesan dönem; fiziksel, bilişsel, emosyonel ve sosyal değişimleri içeren belirgin büyüme ve gelişmenin olduğu çocukluk ve yetişkinlik arasındaki geçiş dönemidir (McCarvill, ve Weaver, 2014). 
Adölesan dönemde yaşanan bu değişikliklere ek olarak kronik bir hastalıkla mücadele eden adölesanın, stres, depresyon ve kaygı durumuna ilaveten tedaviye adaptasyonunu zorlaştırabilir. DM fiziksel olarak gözlenemeyen kronik hastalıklarda adölesanın hastalığı inkar etmesi ve hatta tedaviyi reddetmesi durumları daha sık gözlenmektedir (Adal ve ark., 2015; Çavuşoğlu, 2013) Adölesanın yaşam boyu kan glikoz seviyesini izlemek, diyetine ve aktivite düzeyine göre insülin dozunu ayarlamak ve uygulamak, olası tıbbi komplikasyonlardan korunmak zorunda olması adölesana ek bir yük oluşturmaktadır (Compas, Jaser, Dunn, ve Rodriguez, 2012; Kakleas, Kandyla, Karayianni, ve Karavanaki, 2009) Tip 1 DM tanısı ile takip edilen adölesanın izlemi, ekip olarak aile temelli yürütülmelidir. Ekipte önemli bir yeri olan hemşire adölesanın sürekli izlemini, gerekli bakım ve eğitimini üstlenmelidir (Hemşirelik Yönetmeliği, 2011). Tip 1 DM tanısı olan adölesanın eğitimde holistik bir yaklaşımla hemşirelik kuram ve modellerinin kullanılması bakım ve eğitim aşamalarını kolaylaştırmaktadır (Şengün, Üstün, ve Bademli, 2013) Hemşirelik kuramları, hemşirelik mesleğinin gelişim ve profesyonelleşmesine katkıda bulunur. Bu nedenle hemşirelik uygulamalarında kuram ve modellerin kullanımının yaygınlaştırılması gerekmektedir (Ünsal ve Kızılcı, 2010; Felipe, Araújo ve Vitor, 2014) Hemşirelik teorisyenlerinden Dorothea Elizabeth Orem, insan ve çevre arasında karşılıklı etkileşim olduğunu savunmaktadır. Orem teorisinde, insanın eşsiz bir varlık olduğunu ve çevresinden ayrı düşünülemeyeceğini belirterek; insan, sağlık, çevre ve hemşirelik kavramlarının tanımlarını da bu görüş doğrultusunda yapmıştır (Fawcett, 2005). Öz Bakım Eksikliği Hemşirelik Kuramı, hemşirelik uygulamalarında en sık kullanılan teorilerden biridir. Öz Bakım Eksikliği Kuramı, kişinin ne zaman ve nasıl bir hemşirelik bakımına ihtiyacı olduğunu saptamayı kolaylaştırmaktadır (Orem, 2001). Orem üç tip öz bakım gereksinimi tanımlamaktadır; 1. Evrensel öz bakım gereksinimleri 2. Gelişimsel öz bakım gereksinimleri ve 3. Sağlıktan sapma durumlarında öz bakım gereksinimidir (Orem, 2001). Tip 1 DM tanısı bulunan adölesanın destekleyici ve eğitsel hemşirelik yaklaşımlarına ihtiyaç duymaktadırlar. Bu çalışmada Tip 1 DM tanısı olan bir hastanın Öz Bakım Eksikliği Hemşirelik Kuramı́na göre hemşirelik bakımı incelenmektedir.

\section{Olgu:}

11 yaşında adölesan kız 3-4 aya yakın bir zamandır poliüri ve polidipsi şikayetleri yaşamaktaymış. 6.sınıf öğrencisi olan hasta babaanne, dede ve 4 kardeşi ile birlikte köyde yaşamaktadır. Baba hayvancılıkla uğraşmakta, anne ev hanımıdır. Hasta 2 gün önce baygınlık nedeniyle ailesi tarafından acile götürülmüştür. Acil serviste yapılan kan testleri sonucunda HbA1C: $8 \mathrm{mg} / \mathrm{dL}$ Glukoz: 357 mg/dl, idrar keton: ++ saptanmıştır. Aile hikayesinde babaannesinde DM olduğu ve oral antidiyabetik ilaç kullandığı saptanmıştır. Acilden çocuk servisine yatışı yapılmıştır.

Erzurum Bölge Eğitim ve Araştırma Hastanesi Çocuk Servisi'nde 20.03.2019 tarihinde yatmakta olan R.T'ye Orem'in Öz Bakım Eksikliği Hemşirelik Kuramı kullanılarak yapılan bakım aşağıda verilmiştir.

1-Temel durumsal faktörler:

- Yaş: 11

- Cinsiyet: $\mathrm{K} \mathrm{z}$

- Sağlık durumu: Tip 1 diyabet (Diabetes Mellitus)

- Gelişim durumu: Kilo; 33 kg / 10-25 percentil, boy; 148 $\mathrm{cm} /$ 50-75percentil

- Sosyo-kültürelözellikler:Erzurum'a bağlı birilçede ba- baanne, dede ve 4 kardeşinin de dahil olduğu geniş ve sosyo-ekonomik düzeyi düşük gecekondu tipi bir evde yaşıyor.

- Sağlık bakım sistemi: Anne

- $\quad$ Aile sistemi: Geniş aile

- Yaşam şekli: Günlük yaşam aktiviteleri dışında egzersiz yapmamakta.

- Çevresel durum: Kalabalık bir ailede yaşayan R.T'nin kendine özel bir odası bulunmamakta, kardeşleriyle birlikte aynı odada kalmaktadır. Evin ısınmasını kömür sobası ile sağlanmaktadır. Boş zamanlarında kardeşleriyle oynuyor ve ev işlerine yardım ediyor. Bu durum R.T'nin hem beslenme hem de fiziksel aktivite durumlarını negatif etkilemektedir.

- Kaynakların varlığı-yeterliliği: Ekonomik durumlarının zayıf olduğunu ve diyabetin tedavisinde kullanılan glikometre, strip ve iğne ucunu karşılamakta sıkıntı yaşayabileceğini düşünüyor.

- Hava: Solunumu normal olup, solunumla ilgili güçlük yaşamamaktadır.

- Su: Günlük sıvı alımı 1 litre civarındadır. Ancak diyabete bağlı poliüriden dolayı sıvı alımını arttırması gerekmektedir.

- Beslenme: Beslenme düzeninin olmadığını, iştahsız olduğunu söylemektedir. Kan şekerini dengede tutmak için öğünlerin düzenli ve atlanmadan alınması ve özellikle ara öğün zamanı derste olması ve unutabileceğinden çekiniyor.

- Boşaltım ve dışkılama: İdrar yapma sıklığı günde 10-12 kere ve gaita kontrolü normal, günde 1 kere defekasyon mevcut.

- Aktivitevedinlenme:Düzenlibirfizikselaktivitealışkanlığı yoktur. Günde 8-10 saat uyduğunu belirtmektedir.

- Tehlikelerden koruma: Oluşabilecek hiperglisemi ve hipoglisemi ataklarıyla ilgili olarak kaza ve travma riski taşımaktadır.

- Sosyal etkinlik: Arkadaşlarıyla oyun oynamak dışında herhangi bir sosyal etkinliği bulunmamaktadır.

2-Öz bakım:

- Öz bakım ajanı: Çocuk

- Bağımlı bakım ajanı: Anne

- Hastalık tanısı yeni aldığı için tedirginlik hissediyor.

3-Öz bakım gücü:

- Kendine güven ve saygısı: İletişim esnasında yeterli göz teması kurmuyor

- Enerjisini kontrol etme ve başlatma becerisi: İsteksiz

- Anlama yeterliliği: Hastalık tanısını yeni aldığı için tam adapte olamadığından bazı durumları anlama ve algılamada sıkıntı yaşıyor.

- Motivasyon: Diyabet hemşiresi motive ediyor. Anne hastalığı kabullenemediği için tedirgin ve çocuğuna gereken desteği gösteremiyor.

- Öz bakımı hakkında karar verebilme: Annesiyle birlikte karar veriyor.

- Teknik bilgi elde etme ve uygulama becerisi: Teknik bilgisi yeterli değil.

- Algısal, bilişsel durumu ve iletişim becerisi: Hastane ortamında ilk kez bu kadar uzun süre bulunuyor olması ve kronik bir hastalıkla yaşayacak olmasından kaynaklanan algısal, bilişsel ve iletişimle ilgili sıkıntı yaşamaktadır. 
- Hedeflerine ulaşmak için öz bakım davranışlarını düzenleme ve öz bakım davranışlarını bireysel ve toplumsal yaşamına entegre etme becerisi: İstenilen düzeyde değil.

4- Terapötik Öz bakım gereksinimleri:

Öz bakım gereksinimleri üç alt boyutta incelenmektedir (Orem, 2001).

I-Evrensel öz bakım gereksinimleri:

- Beslenme: Beslenmesine dikkat etmemesi ve persentilinin düşük olması.

- $\quad$ Ağız sağlığı: Dişlerinde çürükler var, dişlerini düzenli fırçalama alışkanlığı yok.

- $\quad$ Aktivite: Yeterince aktif değil. Boş zamanlarını televizyon izleyerek geçiriyor.

- Uyku: Uyku düzeni normal. Günde 8-10 saat uyuyor.

- Bilişsel algılama: Bilişsel algılaması hastalık tanısını yeni aldığından dolayı zorlandığı durumlar olmakta. Derslerinde başarılı.

\section{II-Gelişimsel öz bakım gereksinimleri:}

- Ergenlikle ilgili dönem özellikleri gösteriyor (fiziksel gelişim; boy uzaması ve kas gelişimi hızlı).

- Akranlarıyla iletişimi iyi, hastalığından tedavisi dolayısıyla okuldan ayrı kaldığı için üzgün.

- Hastalığına oryantasyonu henüz istenilen düzeyde değil. İnsülin kullanma durumlarına karşı duyarlı. Önerilen düzeyde kullanmaya gayret gösteriyor.

III-Sağlıktan sapma öz bakım gereksinimleri:

- Kilo kaybı (2 ayda 5 kilo vermiş)

- Diyabetinin olması (Tip 1 diyabet)

\section{5- Öz bakım eksikliği:}

Bağımlı bakım ajanının gücü: R.T annesi okur-yazar, çalışmıyor ve hastalık konusunda bilgi düzeyi yeterli değil. Diyabetle başa çıkmada; öz bakım becerisinin yüksek olması ve öz bakım konusunda pozitif tutumun önemi göz ardı edilmemeli. Aile bireylerinin bakıma katılımının sağlanmasının diyabetli adölesanın öz bakımını olumlu yönde etkileyeceği düşünülmektedir.

\section{6- Hemşirelik gücü:}

Öz bakım gereksinimleri üç alt boyutta incelenmektedir (Orem, 2001). Tip-1 diyabet tanısı alan 11 yaşında kız hastanın öz bakım gereksinimlerini etkileyen faktörler arasında, hastalık tanısının yeni alınmış olmasına bağlı adaptasyon sorunlarının fazla, destek mekanizmalarının ve bakım vericilerin bilgi düzeyinin yetersiz olduğu saptanmıştır. Hastanın öz bakım gücünün, algısal, bilişsel ve duyusal yeterliliğinde sıkıntılı durumlar görülmüştür. Orem'e göre hastanın en önemli sağlıktan sapma gereksinimleri; diş, üriner, beslenme problemleri, fiziksel egzersizde yetersizlik, stresle baş etmede yetersizlik, bakımını üstlenmede eksiklik, hastalığı hakkında bilgi eksikliği olarak belirlenmiştir.

\section{Girişimler:}

\section{I-Sosyal sistem:}

- Adölesanla güven verici ilişki kurulması planlandı.

- Insülin uygulaması gerektiren durumlar hakkında annesine ve kendisine eğitim verildi.

- Okulda meydana gelebilecek beklenmedik durumlara karşı öğretmenlerin ve okul yönetiminin bilgilendirilmesi hakkında uyarılar yapıldı.
- Ayrıca hastalığı ve riskler göz önünde bulundurularak değerlendirme yapıldı.

\section{II-Kişiler Arası Sistem:}

- Anne hastalıkla ilgili bilgi sahibi olmadığı için ve daha önce çocuğunu doktora getirmediği için suçluluk duyuyor.

- Adölesan göz iletişimi kurmaktan kaçınıyor, çekingen davranıyor.

- Adölesanın hastalığı ile ilgili öğretmenlerine ve okul yönetimine bilgi verilmesi gerektiği anlatıldı.

\section{III-Profesyonel - teknolojik sistem:}

- Adölesanın diyabet tedavisindeki son gelişmeleri takibi için insülin pompasına yönelik bilgi verildi.

\section{7- Hemşirelik sistemleri:}

Hemşirenin Belirlediği Sorunlar:

- Düşük benlik saygısı

- Yetersiz ve dengesiz beslenme

- Aktivitede yetersizlik

- Stresle baş etmede yetersizlik

- Bakımını üstlenmede eksiklik

- Hastalığı hakkında bilgi eksikliği

- Akranlarıyla görüntü olarak farklı olması

- Yetersiz çevresel destek

Orem'in teorisine göre üç hemşirelik sistemi bulunmaktadır. Ancak vakaya uygun olması nedeniyle destekleyici ve eğitici hemşirelik sisteminin kullanılmasına karar verildi.

\section{Vakanın Seçimi ve Uygulama Süreci}

Vaka çocuk sağlığı ve hastalıkları dersi uygulamasında belirlendi ve izlenmeye başlandı. Adölesanın ebeveyninden Bilgilendirilmiş Onam alındı. Servisten taburculuğuna kadar gerekli girişimler planlandı ve uygulandı. Hemşirelik girişimleri yazar tarafından gerçekleştirdi. Baba köyde hayvanlarla ilgilendiği için görüşme yapılamadı.

Destekleyici ve Eğitici Hemşirelik Sistemine Göre Uygulamalar:

\section{I-Destek olma:}

- R.T'nin ani gelişen hastalık durumuna adaptasyonunu artırmak için aynı tanıyı almış diğer çocuklarla tanışması sağlandı.

- Çevresindeki insanlarla iletişime geçebilmesi için ortam oluşturma, insanlarla göz teması kurabilmesi ve konuşması desteklendi.

- Hemşireyle göz iletişimi kurabilmesi ve konuşmasını sağlamada destekleme: Adölesan ile hemşirenin sürekli iletişime geçmesi sağlandı. Adölesanı tanımak ve anlamak için girişimlerde bulunuldu. Hemşireye güven duygusunun oluşması için adölesanın sorunlarıyla ilgilenecek günlük bir zaman dilimi belirlendi. Hemşirenin adölesanı başarılı olduğu her uygulama sonrası onu desteklemesi sağlandı.

- Kendini ifade etmesi sağlandı.

- Stresle baş etme yöntemlerini kullanması için eğitilmesi: Adölesanın stresle baş etmesi için stresini yönetme, baş etmede kullanabileceği, kendini ifade etmesini sağlama gibi yöntemler öğretildi. Ayrıca stres yaratan durumların azaltılması için aile yapılan uygulamalara dahil edildi. 
- Gerekli değişimlerin sağlanamaması halinde psikoloğa başvurmanın öneminden bahsedildi.

- Annenin güvenini sağlama, hastalığın yönetimiyle ilgili sadece yardımcı rol üstlenmesini, primer yönetenin adölesan olmasını sağlama: Anne ile işbirliği içerisine girerek adölesanın kendi öz bakımını yerine getirmesi için yardımcı olundu.

- Hastalığıyla ilgili sorumluluk almasını sağlama: Multidisipliner çalışma ve yapılan uygulamalar sonucu kendi öz bakım sorumluluğunu alması sağlandı.

\section{II-Rehberlik etme:}

- Hastanın anlayabileceği düzeyde diyabet ve nedenleri hakkında bilgiler verildi.

- Görüşmelerin sonlarında hastanın soru sormasına izin verilerek, açıklamalarda bulunuldu. Hastaya uzak durması gereken durumlar hakkında bilgi verildi (beslenme hataları, insülinin atlanması, yetersiz sıvı alımı, stres, anksiyete gibi).

- Hasta günlük olarak en az 2 litre su tüketmesi ve diyetine uygun beslenmesi konusunda desteklendi.

- Annenin adölesana öz bakımını geliştirmede yardımcı olmasını sağlandı.

\section{III-Çevresel düzenleme yapma:}

- Hastanın hiperglisemi ya da hipoglisemi atakları sırasında travma ve kazalardan korunması için belirti hissettiği zaman güvenlik önlemleri alması gerektiğinin önemi vurgulandı.

- Travma ve kazalardan korunmak için uygulaması gereken güvenlik önlemleri (çok sıcak banyo yapmaması ve oturarak banyo yapmasının daha güvenli olacağı gibi) hakkında bilgi verildi.

- Evde ve okuldaki iletişiminin nasıl olduğu sorgulandı.

- $\quad$ Ailesiyle iletişimi gözlemlendi.

- $\quad$ Öğretmenler ve ailesiyle iletişime geçilerek işbirliği için bilgilendirme yapıldı.

- Öğretmenler ve ailesine diyabet ve dikkat edilmesi gereken konular hakkında eğitim verildi.

- Stresle başa çıkma konusunda bilgilendirildi

- Evde ve okulda diyabeti tetikleyen faktörleri belirleme, azaltma ya da ortadan kaldırma konusunda bilgilendirildi.

\section{IV-Hastalık tedavisinin öğretimi:}

- Adölesanın açlık ve tokluk kan şekeri takipleri yapıldı.

- Adölesan hipoglisemi ve hiperglisemi belirtileri yönünden takip edildi.

- Adölesanın deri ve doku bütünlüğüne özen gösterildi.

- Adölesana uygun beslenme programları oluşturuldu.

- Adölesanın öğünlerine göre ilaç saatleri düzenlendi.

- İnsülinlerini tam saatinde uygulanmasına dikkat edildi.

- Adölesana uygun fiziksel aktivite programları oluş̧turuldu.

- Adölesana insülin kullanımı hakkında bilgi verildi (insülin bölgeleri ve uygulama saatleri vb.)

- Stresle baş etme yöntemleri öğretildi.

\section{Değerlendirme ve Değişimler}

Adölesanın,

- Kendini daha iyi ifade edebildiği, göz iletişimi kurabildiği ve hemşireyle iletişime geçebildiği,
- Öğrendiği stresle baş etme yöntemlerini uygun şekilde kullandığı,

- Hastalığıyla ilgili risk oluşturabilecek durumları öğrendiği ve bunlardan uzak durmaya çalıştığı,

- Hastalıklarıyla ilgili beslenme, egzersiz, stres yönetimi, ilaç kullanımı konularında verilen eğitimleri hayata geçirdiği,

- Öğretmenlerin adölesanın hastalığının farkında olduğu,

- Hastalığın yönetimiyle ilgili adölesanın primer yönetimde olması için verilen görevleri kendisinin yerine getirdiği,

- Öz bakım sorumluluğunu almaya başladığı gözlemlendi.

\section{Sonuç}

Diyabet hastalığı gerek ülkemizde gerek dünyada ciddi bir sağlık sorunu olarak karşımıza çıkmaktadır. Türkiye'de diyabetin son yıllarda adölesan nüfusta arttığı görülmektedir. Diyabetli bireylerin sağlıklarının korunması ve geliştirilmesi önemlidir. Diyabetli adölesanların öz-bakımlarını yapabilmeleri için hastalığı hakkında bilgiye ve motivasyona gereksinimleri vardır. Hemşire, eğitim ve danışmanlık rolleri ile adölesanın bilgi eksikliğini, öz bakımı ile ilgili uygulama yetersizliğini giderebilir ve kendi bakımının sorumluluğunu üstlenmesine yardımcı olabilir. Hemşire adölesana bilgi verirken ve psikolojik destek olurken; onu dinlemeli, kendisi ile ilgili kararlara katılımını desteklemeli, değerlerine ve inançlarına saygı duymalı, ailenin öz-bakıma katılımını sağlamalı ve adölesanın olumlu ve güçlü yönlerini desteklemelidir. Tip 1 diyabeti olan çocuk ve ailesinin, diyabet yönetiminde mevcut sağlık davranışlarındaki eksikliklerin saptanması ve bu davranışların kazandırılmasında Orem'in kuramı hemşirelere rehberlik etmektedir. Orem'in Öz Bakım Eksikliği Kuramı doğrultusunda değerlendirilen olguda; R.T'nin diyabet yönetiminde sağlık davranışlarından düzenli kan şekeri ölçümü ve insülin enjeksiyonuna adaptasyon sağladığı ancak beslenme ve fiziksel aktivite noktalarında henüz tam adapte olmadığı saptanmıştır.

\section{Çıkar Çatışması}

Çalışmaya engel teşkil edecek herhangi bir çıkar çatışması yoktur.

\section{Yazarın Katkı Düzeyi}

SES: Fikir, tasarım, veri toplanması ve/veya işlemesi, analiz ve/veya yorum, literatür taraması, kaynaklar, yazının yazılması.

\section{Kaynaklar}

1. Adal, E., Onal, Z., Ersen, A., Yalcin, K., Onal, H, \& Aydin, A. (2015). Recognizing the psychosocial aspects of type 1 diabetes in adolescents. Journal of Clinical Research in Pediatric Endocrinology, 7(1), 57- 62. https://doi. org/10.4274/jcrpe.1745

2. Compas, B.E., Jaser, S.S., Dunn, M.J, \& Rodriguez, E.M. (2012). Coping with chronic illness in childhood and adolescence. Annual Review of Clinical Psychology, 27(8), 455-480. https://doi.org/10.1146/annurev-clinpsy-032511-143108

3. Craig, M.E., Jefferies, C., Dabelea, D., Balde, N., Seth, A., \& Donaghue, K.C. (2014). ISPAD Clinical Practice Consensus Guidelines 2014 Compendium: Definition, epidemiology, andclassification of diabetes in children and adolescents. Pediatric Diabetes, 15(20), 4-17. https://doi.org/10.1111/ pedi.12186

4. Çavuşoğlu, H. Çocuk Sağlığı Hemşireliği, Cilt 1 (11. Baskı). Ankara: Sistem Ofset Basımevi. 2013, s.s.77

5. Fawcett J. Contemporary nursing knowledge: analysis and evaluation of conceptual models of nursing. Second edition, USA: FA Davis Comp; 2005, p.p 223- 319

6. Felipe LC, Araújo ARA, \& Vitor AF. (2014). Nursing process according the model of self-care in a cardiacbedidden patient. Journal of Research Fundamental Care Online. 6(3):897-908. https://doi.org/10.9789/2175- 
$5361.2014 v 6 n 3 p 897$

7. Hemşirelik Yönetmeliği (2011). Hemşirelik Yönetmeliğinde Değişiklik Yapımasina Dair Yönetmelik. Resmi Gazete, No: 27910, Erişim Tarih: 19 Nisan 2019.

8. International Diabetes Federation. IDF Diabetes Atlas, Nineth Edition. https://www.diabetesatlas.org/en/. 2019. Erişim tarihi: 01.04.2021

9. Kakleas, K., Kandyla, B., Karayianni, C., \& Karavanaki K. (2009). Psychosocial problems in adolescents with type 1 diabetesmellitus. Diabetes\&Metabolism, 35(5), 339-350. https://doi.org/10.1016/j.diabet.2009.05.002.

10. Kalyva, E., Malakonaki Eiser, C., \& Mamoulakis, D. (2011). Health-related quality of life (HRQoL) of children with type 1 diabetes mellitus (T1DM) self and parental perceptions. Pediatric Diabetes, 12, 34-40. https://doi.org/10.1111/j.1399-5448.2010.00653.x

11. McCarvill, R., \& Weaver, K. (2014). Primarycare of female adolescents with type 1 diabetesmellitus and disordered eating. Journal of Advanced Nursing, 70(9), 2005-2018. https://doi.org/10.1111/jan.12384.

12. Orem, D.E. (2001). Self-care deficit theory of nursing: concepts and applicati ons USA: Dennis, C.M. Mosby-Year Book Inc: 7 ed. pp.99-135.

13. Şengün İnan, F., Üstün, B. ve Bademli, K. (2013). Türkiye'de kuram/modele dayalı hemşirelik araştırmalarının incelemesi. Anadolu Hemşirelik ve Sağlık Bilimleri Dergisi, 16:(2):132-139.

14. Ünsal Avdal, E. ve Kızılcı, S. (2010). Diyabet ve özbakım eksikliği hemşirelik teorisinin kavram analizi. Dokuz Eylül Üniversitesi Hemşirelik Yüksekokulu Elektronik Dergisi, 3(3):164-8. 